\title{
A Supplier Selection Model for a Wholesaler and Retailer Company Based on FITradeoff Multicriteria Method
}

\author{
Inêz Manuele dos Santos, Lucia Reis Peixoto Roselli $\mathbb{D}^{\mathbb{D}}$, André Luiz Gomes da Silva, \\ and Luciana Hazin Alencar

\begin{abstract}
Management Engineering Department, Universidade Federal de Pernambuco, Avenida da Arquitetura, Cidade Universitária,
\end{abstract} \\ CEP:50740-550, Recife, PE, Brazil
}

Correspondence should be addressed to Luciana Hazin Alencar; alencarlh@gmail.com

Received 2 April 2020; Revised 11 August 2020; Accepted 20 August 2020; Published 23 October 2020

Guest Editor: Tomasz Wachowicz

Copyright (C) 2020 Inêz Manuele dos Santos et al. This is an open access article distributed under the Creative Commons Attribution License, which permits unrestricted use, distribution, and reproduction in any medium, provided the original work is properly cited.

\begin{abstract}
The problem approached is regarding supplier selection in a wholesaler and retailer of the construction sector. The current approach used in the company analyzed for the supplier selection problem is unable to evaluate the many issues that the company considers must be addressed. Thus, the Flexible and Interactive Tradeoff (FITradeoff) ranking method was chosen to deal with this problem. It seeks to elicit criteria weights in a decision problem, using partial information about the decision maker's (DM's) preferences in order to choose the most attractive alternative, based on the ranking of the suppliers provided. Based on the Hasse diagram developed when applying the method, the DM makes some observations regarding the suppliers' positions in the ranking. Bar graphics and radar graphics were also used and these enable the DM to evaluate each supplier better. It was perceived that the method is applicable and well accepted by the DM. The graphic part helps the DM in understanding the analysis of the problem, offering no barriers to proceed with the tradeoff. Thus, for this situation of selecting a supplier in a wholesaler and retailer of the construction sector, the DM felt comfortable with the proposed approach using the FITradeoff multicriteria ranking method and with the results presented, and the proposed approach is shown to be adequate.
\end{abstract}

\section{Introduction}

The process of selecting partner companies in the supply chain is an important strategic factor in achieving maximum results when using intercompany relationship management and collaboration, but, prior to forming alliances with suppliers, it is necessary to identify which of them are potentially beneficial. Given a scenario where long-term relationships with partners are established to maximize company results, it is observed that establishing the criteria and the way in which partners (suppliers) are chosen are very important issues when constructing supply chains and distribution channels, and, consequently, for generating the advantages that can arise from closer relationships between buyers and suppliers.

The supplier selection process is very important for medium and small organizations since they have limited resources and operational capacity. Therefore, by ensuring that they select suitable suppliers, they can obtain more significant gains for the business, thus increasing the performance and profitability. It is usually the case that smalland medium-sized companies only use a single criterion, often the "price/cost," to select and classify the type of relationship they wish to have with suppliers, even though this is only one of the components of the decision-making problem. In contemporary supply chain management (SCM), multiple criteria are used to evaluate potential suppliers against a single cost factor [1]. Another important issue for these companies is the weighting of selection criteria, where the DM tends to assign the same degree of importance to all the criteria or has difficulties understanding what factors are strategically important for the business.

It is known that supplier selection is a multicriteria decision-making/aiding (MCDM/A) problem that depends 
on a wide range of factors that involve both quantitative and qualitative factors, such as quality, cost, capacity, delivery, and technical potential [2-4]. MCDM/A problems consist of decisions in which there are at least two alternative actions to evaluate with regard to two or more attributes [5-7], which is the situation in most supplier selection processes. These decisions are made to meet multiple goals that often conflict with each other. In order to support the decision-making process in a multicriteria problem, multicriteria methods that lead to solving the problem must be used. Many decisions in business organizations are based on MCDM/A approaches, which have been applied in many situations and different contexts, such as in newsvendor problem [8], maintenance strategy [9], portfolio selection of projects [10], and risk analysis of hydrogen pipelines [11].

The supplier selection process usually involves evaluating suppliers in relation to a set of criteria previously defined by the company, in which the supplier or suppliers that best meet the criteria will be selected. In addition, there must be a rigid process for evaluating the selected suppliers in order to support the management of relationships in the long term and to ensure productivity, profitability, and success in achieving the objectives expected as a result of the relationships between a company and its suppliers [12]. According to Araújo et al. [13], the quality of the suppliers selected depends on the quality of the selection process. Thus, the types of criteria, the information level that is required and available, the type of information (complete or partial), the problematic approach (ranking, selection of one supplier, or selection of a subgroup of suppliers), and other factors must be considered when selecting the methodology used for the supplier selection problem, since each criterion is adequate for a set of specific conditions (Araújo et al. [3]). Palha et al. [14] state that criteria used in the selection of suppliers vary in relation to the priority given by the clients as a result of a tradeoff process; also some of these criteria could be subjective and probabilistic.

Many supplier selection multicriteria models have been proposed in the management literature for dealing with supplier selection problem $[1,15]$. Nevertheless, when using additive methods, establishing statements of indifference between consequences, caused by the application of traditional methods, is a difficult task for some DMs, and they may not be able to provide the necessary information [7]. In addition, the process used to obtain the criteria weights by traditional methods require a lot of time from the DM [15]. Considering this context, approaches that use partial information are required [16-18].

Thus, given the supplier selection problem in a deterministic context, this study aims to propose a multicriteria model to support the supplier selection process in a company that is a retailer and wholesaler of waterproofing products. The model is based on the Flexible and Interactive Tradeoff (FITradeoff) method for the ranking order problem $[17,18]$. It is worth mentioning that a multicriteria model for a supplier selection in a food company using the FITradeoff method for the choice problematic is already presented in the literature [18]. The main characteristic of this methodology in relation to the traditional Tradeoff method [5] is that FITradeoff works with partial information about the DM's preferences [16]. Besides, our study presents graphical visualization analysis, which was drawn from a recent study [19-21] that uses the neuroscience approach, to investigate how DMs understand MCDM/A problems represented by graphics. This feature contributes mainly to how graphics can be used to support the DM to tackle an MCDM/A problem. It is a flexible tool that can improve a Decision Support System (DSS).

The paper is organized as follows: Section 2 contains a brief literature review about supplier selection processes. Section 3 describes how the FITradeoff method is used in multicriteria decision problems. Section 4 presents the proposed supplier selection model and its application in the study company, and the last section contains the conclusions of this study and makes suggestions for future lines of research.

\section{Supplier Selection Process}

Supplier selection is one of the most critical activities of the procurement process in a SCM because a wrong choice can lead to the supply chain as a whole suffering loss, thus directly affecting the performance of the organizations involved $[13,18]$. In this context, suppliers should be selected by using formalized methods that ensure that the selection process is reviewed and evaluated and therefore the company's decision-making process is more readily able to choose the suppliers that best align with the company's objectives and supply chain [22].

According to Chen and Chao [12], the supplier selection process is an important issue in SCM and there are two important aspects to the supplier selection problem: (1) setting the criteria for evaluating suppliers and (2) designing the process or method of selecting suppliers. According to Wibowo and Deng [23], supplier selection processes are complex and challenging owing to DMs' having diverse opinions, to uncertainty and imprecision being present, and to the cognitively demanding nature of the decision-making process.

This process has become increasingly complex due to factors such as globalization and keeping pace with exploiting how the Internet can be used, which has broadened the range of potential alternatives to choose from. However, this process needs to be agile to meet the needs of companies and their clients, and there are some laws or standards that require both transparency when activities are being selected and compliance with new procedures. This leads to companies involving more agents (analysts, specialists, and DMs) in the selection process, who may have divergent objectives [24].

Sarvestani et al. [25] emphasize that the problem of supplier selection has attracted much attention in recent years and is a class of problems that have been widely studied by many researchers. Since there are usually several factors that must be taken into account while selecting suppliers, various multiple-criteria decision-making techniques have been used to evaluate and rank suppliers to ease the selection process [25]. 
Ho et al. [1], De Boer et al. [26], and Chen [27] have conducted extensive reviews of the literature on multicriteria decision-making methods used to support supplier selection. They highlighted the following approaches:

(i) Methods of mathematical programming: an objective mathematical function is developed for the selection problem, where the solution is given by maximization or minimization [27-30].

(ii) Multicriteria model: the DM evaluates a set of alternatives in relation to several decision criteria using a systematic method. Weighting methods are commonly used. In this case, the DM assigns subjective weights to each criterion and the overall assessment is based on the sum of the performances in the criteria of each supplier multiplied by the weight of the criteria [31,32]. The AHP (analytic hierarchy process) [33-35] and the ANP (analytic network process) $[36,37]$ are other highlighted methods.

(iii) Data envelopment analysis (DEA): the DM evaluates the alternatives to the benefit criteria (outputs) and the cost criteria (inputs). The alternative is chosen using the ratio of the weighted sum of its outputs to the sum of its inputs [38-40].

(iv) Total cost of ownership (TCO): all measurable costs incurred during the life cycle of the purchased item are incorporated into how a supplier is chosen [41-43].

(v) Fuzzy theory: linguistic values are expressed in fuzzy numbers, which are used to evaluate and assign weights to the criteria $[44,45]$.

(vi) Artificial intelligence: the decision problem is modeled and solved by means of a computational system [46-48].

The models based on these methods aim to encompass the maximum number of possible criteria and reduce the subjectivity of the decision. De Boer et al. [26] argue that factors such as the number of suppliers available, the importance of the purchase and/or the relationship with the supplier, and the existing amount of uncertainty determine the most appropriate method to be used, depending on the purchase characteristics (new purchase, modified rebuy, straight rebuy, or strategic rebuy). It is observed that most of the models combine more than one technique for structuring and solving supplier selection problems $[1,27]$.

Another fundamental aspect is to establish the most important criteria in a decision problem. Araújo et al. [13] identified 21 different criteria applied to the supplier selection problem in the recent literature. Ho et al. [1] also identified from their review of the literature what the most popular criteria were which DMs considered in order to evaluate and select the most appropriate supplier. Hundreds of criteria were proposed, among which the most commonly chosen criterion is quality, followed by delivery, price/cost, manufacturing capability, service, management, technology, research and development, finance, flexibility, reputation, relationship, risk, safety, and environmental impact. As can be seen, price/cost is not the most widely adopted criterion. Ho et al. [1] further state that the traditional single-criterion approach based on lowest cost bidding is no longer sufficiently supportive of or robust in contemporary SCM.

Araújo et al. [3] carried out an extensive literature review on 119 papers, as to supplier selection models, which were published between 1973 and 2015. They identified three key points: (1) Many factors are usually considered when selecting suppliers, as it is important for the process of building decision-making models to consider several criteria that aid finding solutions for supplier selection problems. (2) Choosing adequate criteria for supplier selection depends on the needs and priorities of the purchasing company; thus, each model should be built according to that company's needs. (3) Criteria that evaluate the degree of a supplier's engagement are not often found in the literature, although satisfying such criteria is essential to establishing good partnerships.

Because each organization has its own strategic interests, the decision problem needs to be structured within its specific context. Thus, by considering the DM's rationality, the ranking problem, and the need for a more flexible method for setting the parameters, the supplier selection problem in this study is built based on a multicriteria additive aggregation approach, considering the FITradeoff method, as presented in the following section.

\section{FITradeoff Method}

Flexible and Interactive Tradeoff (FITradeoff) [16] is a method developed to elicit a criteria-scaling constant in the context of Multiattribute Value Theory (MAVT) [5, 7]. In the MAVT context, given a set of alternatives, the first alternative in the ranking is the one that presents the highest global value, as illustrated in equation (1), where $k_{i}$ is the scaling constant for criterion $i$ and $v_{i}\left(x_{i}\right)$ is the marginal value function in criterion $i$.

$$
V(A)=\sum_{i=1}^{n} k_{i} v_{i}\left(x_{i}\right)
$$

In the FITradeoff method, the first step is the intracriteria evaluation. After that, the ranking of scaling constants is conducted. In this step, the decision-maker (DM) has to order the scaling constants based on the range of consequences presented in each criterion. Thus, the first inequality is generated, as illustrated in equation (2), where $n$ is the number of criteria. It is worth mentioning that the intracriteria evaluation and the ranking of scaling constants are common steps in most methods in the MAVT context.

$$
k_{1}>k_{2}>\cdots>k_{n}
$$

and, after that, the elicitation process is conducted in the FITradeoff method in order to reduce the scaling constant space (or weight space). In the FITradeoff method, the exact value of the criteria weights is not obtained. Instead of that, a 
weight space is obtained from the preferences expressed by DM during the decision process.

In this context, in the elicitation process, the DMs have to express their strict preferences for some comparisons of consequences. Thus, an intermediate value of consequence, in the criterion which presents the highest value of scaling constant $\left(k_{1}\right)$, is compared to the highest value of consequence $v_{2}\left(x_{2}^{\text {upper }}\right)$ in the criterion associated with the adjacent scaling constant $\left(k_{2}\right)$. In the FITradeoff method, the interval scale is applied; thus the best consequence in a criterion presents value function equal to one, and the worse consequence presented value functions equal to 0 . Thus, given the situation in which the DM prefers to receive the best consequence in Criterion 2 rather than an intermediate consequence in Criterion 1, the inequality illustrated in equation (3) is obtained. Therefore, after each comparison, an inequality is also generated in order to represent the preference expressed by the DM. It is worth mentioning that other consequences, that is, in other criteria, are not compared since the comparison is in pairs, following the scaling constant order.

$$
k_{1} v_{1}\left(x_{1}^{\text {low }}\right) \leq k_{2} \text {. }
$$

An important characteristic of the elicitation conducted in the FITradeoff method is that the DM does not have to identify the exact point of indifference between the consequences, as required in the Tradeoff method [5]. In other words, the FITradeoff elicitation process requires only strict preferences, since this method uses concepts of partial information. Therefore, it is considered an advantage of the FITradeoff method, since identifying the exact point of indifference can lead to $67 \%$ of inconsistencies in the results [7].

After each interaction with the DM, the inequality obtained is included in a linear programming problem (LPP). Thus, the LPP model is processed and the relation between alternatives is updated. In other words, from this LPP model, the scaling constant space is reduced, and some alternatives become dominated from others, as described in [17]. The LPP model is illustrated by the system of equations (4)-(8), where $A_{1}$ represents alternative 1 in the set of alternatives.

$$
\text { Max Dominance }\left(A_{1}, A_{2}\right)=\sum_{i=1}^{n} k_{i} v_{i}\left(A_{1}\right)-\sum_{i=1}^{n} k_{i} v_{i}\left(A_{2}\right) \text {, }
$$

s.t.,

$$
\begin{gathered}
k_{1}>k_{2}>\ldots>k_{n}, \\
k_{i} v_{i}\left(x_{i}^{\text {low }}\right) \leq k_{i+1}, \\
k_{i} v_{i}\left(x_{i}^{\text {upper }}\right) \geq k_{i+1}, \\
\sum_{i=1}^{n} k_{i}=1 .
\end{gathered}
$$

In this context, the DM participates in the whole decision process expressing his/her preferences and evaluating the partial results. Therefore, the FITradeoff method is considered as an interactive method.
The FITradeoff method is implemented by a Decision Support System (DSS), both for the choice problematic [16] and for the ranking problematic [17]. Thus, in the DSS, the holistic evaluation can be conducted to assist the DM during the decision process. Several types of visualization are presented in the DSS, such as bar graphic, bubble graphic, and radar graphic. In the FITradeoff DSS for ranking problematic, the Hasse diagram is also presented to illustrate partial rankings during the decision process.

Therefore, based on graphical visualizations, the DM can define dominance relations between the alternatives in order to reduce the decision process. For the choice problematic, the DM can evaluate the Potentially Optimal Alternatives (POAs), being the set of alternatives which remains in the decision process. Thus, if the DM wishes, he/she can select the final alternative in the group and finalize the FITradeoff process. On the other hand, for the ranking problematic, for alternatives that are incomparable in the partial ranking and can be evaluated in order to define the complete ranking, if the DM wishes, he/she can define a dominance relation between them, obtaining the complete ranking.

In this context, the FITradeoff presents another advantage compared to the traditional tradeoff method, which is the flexibility provided by the holistic evaluation process. Thus, from the holistic evaluation, the decision process can be concluded before the final alternative or the complete ranking is obtained by the LPP model in the elicitation process. The FITradeoff DSS is available by request at http:// www.fitradeoff.org. Figure 1 illustrates the FITradeoff interaction process.

\section{Case Study}

The case study was carried out in a company that operates in the retail and wholesale trading of waterproofing products and services and that has been involved in the civil construction market since 1989. The company is located in the northeast of Brazil, where it has wholesale units and retail stores in two major cities in that region and distributes products to four states. The company stands out in its market of selling waterproofing solutions, for which it aims to offer quality solutions and to be unique in the market. In addition, as one of its management pillars, the company guarantees to search for and supply quality and innovative solutions in waterproofing products in order to satisfy the specific needs of its clients. Therefore, the company needs to have suppliers that are aligned with its strategic objectives. In addition, the supplier selection process should consider the main aspects of service and commercialization that the company expects from its suppliers so that it is better able to lead its market because the excellence of its waterproofing solutions differentiates it from its competitors.

The process of selecting suppliers in the company is carried out based on only two criteria: the cost of products and commercial conditions. This may involve the risk that partnerships may no longer be realized or that partnerships may be entered into based solely on the financial aspects. This also jeopardizes the duration of relationships in the supply chain of the company, since the market 


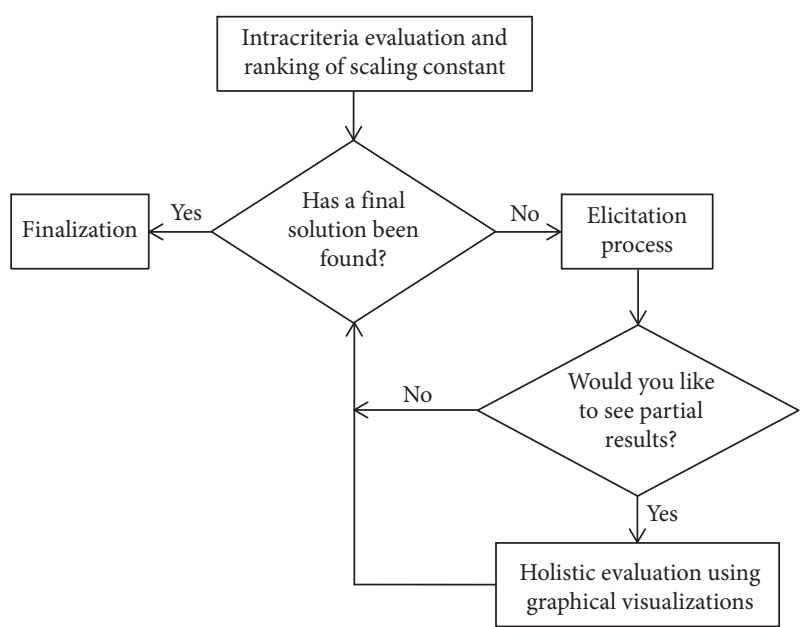

FIGURE 1: FITradeoff process.

requires not only financially competitive products but also other business features that clients value such as availability, reliable delivery time, product quality, productivity, minimizing losses, warranty, after-sales service, and packaging.

Using this process, the company perceives that the selected suppliers are not aligned with all the aspects that the company aims to have with its business partners, thus making it important for it to develop a "most appropriate supplier" selection model.

4.1. Proposed Model for Supplier Selection. The proposed model, based on FITradeoff method, provides assistance to the DM in relation to the process of selecting new suppliers, with the objective of keeping the suppliers in line with the company's plans and objectives. This will contribute to the growth and development of business and its market share of waterproofing products. The DM is the director of the company, a civil engineer, who leads the procurement, commercial, and technical activities of the organization. The proposed model for supplier selection is presented in Figure 2.

The steps of the model shown in Figure 2 are described in detail in the following points.

4.1.1. Identify New Supplier(s). It refers to identifying new suppliers or products to find new requirements or improve the company's current supply performance. Suppliers are classified into homogeneous groups that supply similar materials (stickers, additions, healing agents and release agents, asphalt emulsions, grouts and special mortars, asphalt blankets, polymeric and elastomeric membranes, auxiliary products, etc.) to facilitate the analysis of the participation of each such group of products in the company's results.

4.1.2. Classify the Supplier's Product Mix. The classification will be based on the participation of each group of products in the analysis of the contribution margin of the $\mathrm{ABC}$ curve (a method for classifying materials, according to their cost, based on the frequency of distribution and the Pareto method) for the company's revenue. The supplier selection process will be conducted according to the class of products mix for a given group of materials: mix of class A products (corresponds to $20 \%$ of the company's products, accounting for $80 \%$ of the company's revenue), mix of class B products (corresponds to $30 \%$ of the company's products, accounting for $15 \%$ of the company's revenue), and mix of class C products (corresponding to $50 \%$ of the company's products, accounting for $5 \%$ of the company's revenue). Suppliers will be classified in the product mix classes as follows:

(i) Class A suppliers have at least one item classified in product group A

(ii) Class B suppliers have at least one item classified in product group $\mathrm{B}$ and no items in class $\mathrm{A}$

(iii) Class $\mathrm{C}$ suppliers do not have products classified in classes $\mathrm{A}$ and $\mathrm{B}$

The proposed model was applied to the suppliers classified with a product mix in class A (class A suppliers) for a specific product group. The company's strategic suppliers are included in this class, for which the company has an interest in establishing long-term purchase agreements. In this first stage, 20 suppliers were classified and denominated as S1 to S20.

4.1.3. Prequalify Suppliers. A supplier prequalification process was carried out to identify the suppliers that meet the minimum requirements for submission to the multicriteria selection process. This procedure is necessary to reduce the risk of selecting an inadequate supplier. Criteria used in the prequalification and selection of suppliers are based on studies in [49-51]. The criteria used in the prequalification phase were chosen because they are aligned with the company's business, as shown in Table 1.

The supplier must meet the minimum requirements for each of these qualifying criteria according to its classification (based on the product mix to be supplied) in order to qualify for the supplier selection stage.

The 20 selected suppliers were analyzed against the prequalifying criteria, shown in Table 1, by means of analyzing the documents containing the information required for each criterion evaluated. All 20 suppliers met the minimum requirements and were thus accepted for the supplier selection stage.

4.1.4. Select the Evaluation Criteria. Five criteria were selected by the DM as the most important ones to be used for evaluating the previously selected suppliers, aligned with the expected results of the company. Table 2 presents these criteria.

The evaluation matrix of the suppliers on these criteria is presented in Table 3.

\subsubsection{Apply the Multicriteria Method (FITradeoff Method) and the Rank the Suppliers.}

In order to solve the supplier selection problem, the FITradeoff method for ranking problems was applied [17]. 


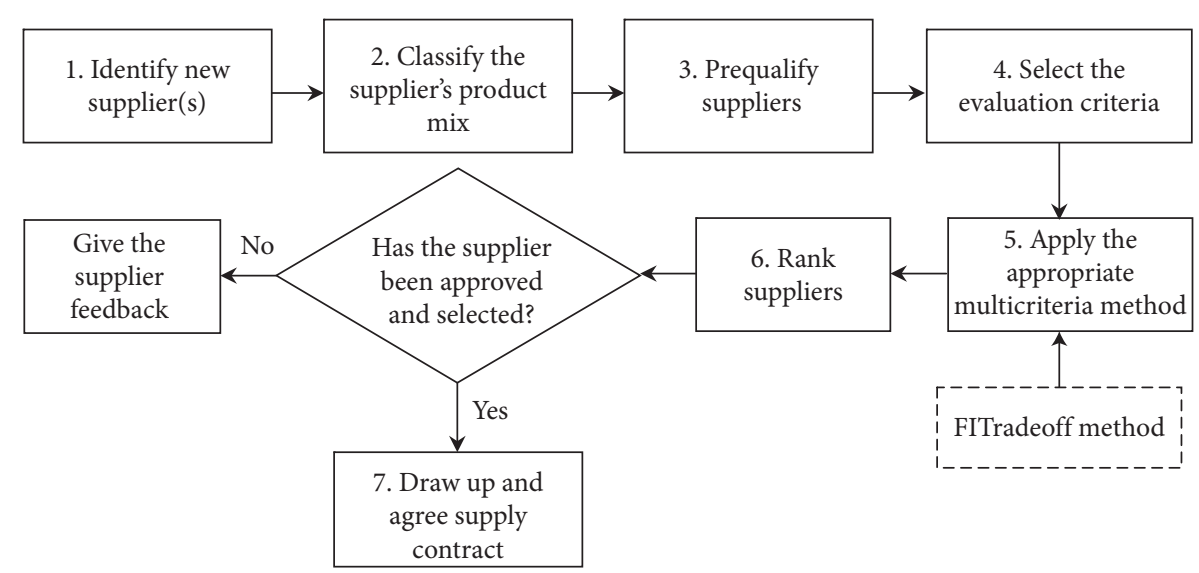

FIgUre 2: Proposed model for supplier selection.

TABle 1: Prequalifying criteria.

\begin{tabular}{|c|c|}
\hline Criterion & Description \\
\hline $\begin{array}{l}\text { Technical } \\
\text { capacity }\end{array}$ & $\begin{array}{l}\text { Measured by validating that the technical documents in support of the content of the contract show that the supplier is } \\
\text { able to provide the materials and services proposed in the supply contract }\end{array}$ \\
\hline Financial status & $\begin{array}{l}\text { Measured by examining the company's latest accounting returns and relating these to the supplier's financial position } \\
\text { in order to be able to assess the potential of the supplier to maintain a long-term partnership under the trading } \\
\text { conditions to be negotiated }\end{array}$ \\
\hline Infrastructure & Measured by examining the documentary evidence of the industrial structure and service that the supplier will offer \\
\hline Customer service & $\begin{array}{l}\text { Measured by a company document that details the communication channels and telephone and electronic support, } \\
\text { which the supplier will offer to the company's customers as the means by which their questions about use, problems, } \\
\text { warranty, reverse logistics, and other issues can be made and answered }\end{array}$ \\
\hline
\end{tabular}

As discussed in Section 3, the first step is the intracriteria evaluation, which is performed in the previous steps and the outcome is Table 3. After that, it is conducted to ranking of scaling constants. Thus, according to the DM's preferences, the scaling constants concerning criteria $\mathrm{C} 1, \mathrm{C} 4$, and $\mathrm{C} 5$ hold the same position in the ranking, followed by the scaling constant of Criterion $\mathrm{C} 2$, as well as concluding with the scaling constant of the criterion $\mathrm{C} 3$, as illustrated in equation (9).

$$
k_{C 1}=k_{C 4}=k_{C 5}>k_{C 2}>k_{C 3} .
$$

After this step, a partial ranking was obtained, as illustrated in Figure 3: the Hasse diagram. Based on this diagram, it was possible to note that supplier S13 was already indicated as the best solution, as it was still placed first in the ranking. In the second and fourth positions, many alternatives were presented. Despite using the Hasse diagram, many relations could be identified; for example, S6 and S20 had equal performances in position 2; S6 dominates S3, and S3 dominates S4. In this context, in order to further complete the ranking, the elicitation process should be conducted.

Hence, the elicitation step was carried out in order to generate more inequalities and specify more relations between the alternatives. In this context, after the second elicitation question in the DSS FITradeoff was answered, the ranking was updated, and this led to the positions being increased from four to seven. Moreover, after the fourth elicitation question, the ranking presented nine positions. The second elicitation question corresponded to comparison of a supplier which had $50 \%$ of performance in the criterion Product Quality (named consequence A) versus consequence B, a supplier that had $100 \%$ of performance in the criterion Flexibility (named consequence B). Given this pairwise comparison, the DM preferred consequence B. Moreover, the fourth question compared a supplier which had $100 \%$ of performance in the criterion Product Quality versus a supplier that had $100 \%$ of performance in the criterion Flexibility. For this other pairwise comparison, the DM preferred consequence A (" $100 \%$ of performance in the criterion Product Quality").

Figure 4 presents the ranking found after the second and fourth questions. The major differences occurred in the middle of the ranking, specifically in position 3, where S4 dropped down to position 4 , and in position 6 , which was split in two. Moreover, it was possible to observe that the first and last alternatives had been defined; namely, S13 remained in first position, S6 and S20 were tied in second position, and S11 remained in last position.

Regarding the main proposition of this study, that is, to generate the ranking of suppliers, further investigations in positions three, seven, and eight might be conducted in order to explore the dominance relations between these alternatives and to generate a more detailed ranking. Thus, based on the Hasse diagram obtained after the fourth question, as illustrated in Figure 5, some comments were 
TABLE 2: Supplier selection criteria.

\begin{tabular}{ll}
\hline Criterion & Description \\
\hline Product quality & $\begin{array}{l}\text { Presentation of quality tests on the supplied product, } \\
\text { carried out internally and externally, and on the } \\
\text { suitability of the results for the specified quality }\end{array}$
\end{tabular}

Scale

Objective

(1) Does not present internal or external quality

tests

(2) It features internal quality testing that does not meet specifications

(3) Features in-house quality testing that meets specifications

Maximize

(4) Features external quality tests that meet specifications

(5) Features internal and external quality tests that meet specifications

(1) Supplier offering a single commercial condition

(2) Supplier offering more than one fixed commercial condition

This concerns commercial flexibility. Degree of

(3) Supplier that negotiates with the client up to

$50 \%$ of the commercial conditions

Maximize

Flexibility (C2) adaptation of the commercial conditions of the

(4) Supplier that negotiates with the client from products and services to the company's needs

$50 \%$ to $90 \%$ of the commercial conditions

(5) Supplier that negotiates with the client $90 \%$ to $100 \%$ of the commercial conditions

(1) Supplier that only carries out commercially related actions

(2) Supplier that only aligns prices to its customer's strategy

Relationship (C3) $\begin{aligned} & \text { Degree of supplier relationship with company } \\ & \text { strategy }\end{aligned}$

(3) Supplier that aligns prices and deadlines to its customer's strategy

Maximize

(4) Supplier that aligns prices, terms, and operations to its customer's strategy

(5) Supplier that aligns prices, terms, operations, information, and development of new products to its customer's strategy

(1) Supplier that has the delivery time until 5 days $(t \leq 5)$

(2) Supplier that has the delivery time between 5 and 10 days $(5<t \leq 10)$

Time (C4)

Time $(t)$ between the sending of the order and the invoicing and shipping of the purchase orders

(3) Supplier that has the delivery time between 10 and 15 days $(10<t \leq 15)$

(4) Supplier that has the delivery time between 15 and 20 days $(15<t \leq 20)$

(5) Supplier that has the delivery time more than 20 days $(t>20)$

(1) Supplier that has the $\%$ contribution of products

(c) to the company's results less than $20 \%$ (c $\leq 20 \%$

(2) Supplier that has the \% contribution of products

(c) to the company's results between $20 \%$ and $40 \%$

$(20 \%<c \leq 40 \%)$

(3) Supplier that has the \% contribution of products

Contribution margin (C5)
$\%$ contribution of products to the company's results (c) to the company's results between $40 \%$ and $60 \%$ $(40 \%<c \leq 60 \%)$

(4) Supplier that has the \% contribution of products

(c) to the company's results between $60 \%$ and $80 \%$ $(60 \%<c \leq 80 \%)$

(5) Supplier that has the \% contribution of products

(c) to the company's results more than $80 \%$. made: in the third position, the alternatives S14 and S17 dominated S19, which do not have a relation with S3 and S15; besides, S3 and S15 were tied. Moreover, from evaluating this diagram, it was observed that, in position seven, S2 dominates S16, and S12 dominates S16 and S7; and in position eight S9 dominates S8 and S18 dominates S1. Therefore, based on these observations, it could be concluded that alternatives S3, S15, S14, and S17 present the best performance in position three, S2 and S12 in position seven, and S9 and S18 in position eight. 
TABLE 3: Evaluation of the suppliers.

\begin{tabular}{lccccc}
\hline Suppliers & C1 & C2 & C3 & C4 & C5 \\
\hline S1 & 3 & 5 & 3 & 4 & 1 \\
S2 & 5 & 1 & 3 & 5 & 3 \\
S3 & 4 & 4 & 5 & 2 & 4 \\
S4 & 4 & 4 & 4 & 2 & 3 \\
S5 & 3 & 4 & 4 & 2 & 3 \\
S6 & 5 & 5 & 5 & 3 & 5 \\
S7 & 3 & 5 & 5 & 4 & 2 \\
S8 & 3 & 3 & 4 & 4 & 2 \\
S9 & 3 & 4 & 4 & 5 & 3 \\
S10 & 4 & 4 & 5 & 3 & 3 \\
S11 & 3 & 2 & 3 & 5 & 3 \\
S12 & 3 & 4 & 5 & 3 & 2 \\
S13 & 5 & 5 & 5 & 2 & 4 \\
S14 & 5 & 3 & 3 & 2 & 4 \\
S15 & 4 & 4 & 5 & 2 & 4 \\
S16 & 4 & 2 & 3 & 4 & 2 \\
S17 & 5 & 4 & 4 & 3 & 4 \\
S18 & 4 & 3 & 3 & 5 & 2 \\
S19 & 5 & 3 & 3 & 3 & 4 \\
S20 & 5 & 5 & 5 & 3 & 5 \\
\hline
\end{tabular}

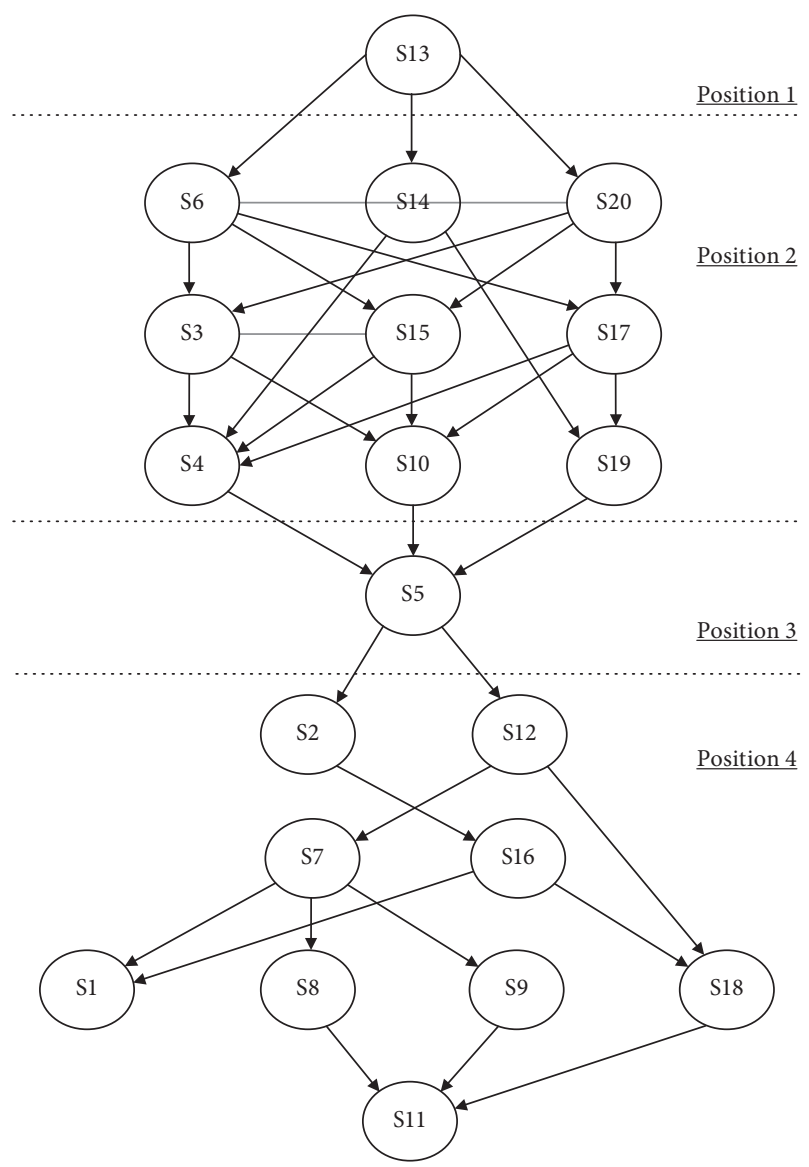

FIGURE 3: Hasse diagram after the step of rank ordering the criteria.

In order to investigate these alternatives in more depth, bar graphics and radar graphics were used. Bubble graphics were not used since they did not perform well in the evaluation of MCDM/A problems in a previous study

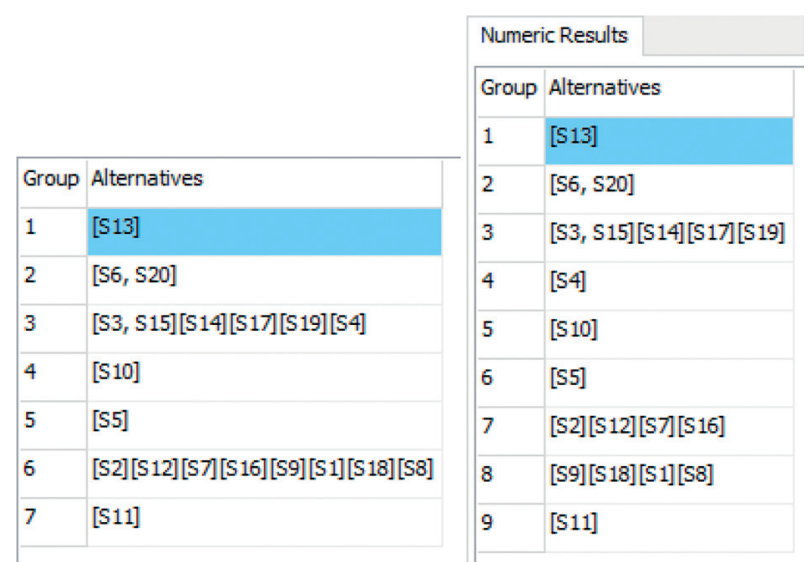

FIgURE 4: Rank order after second and fourth elicitation questions.

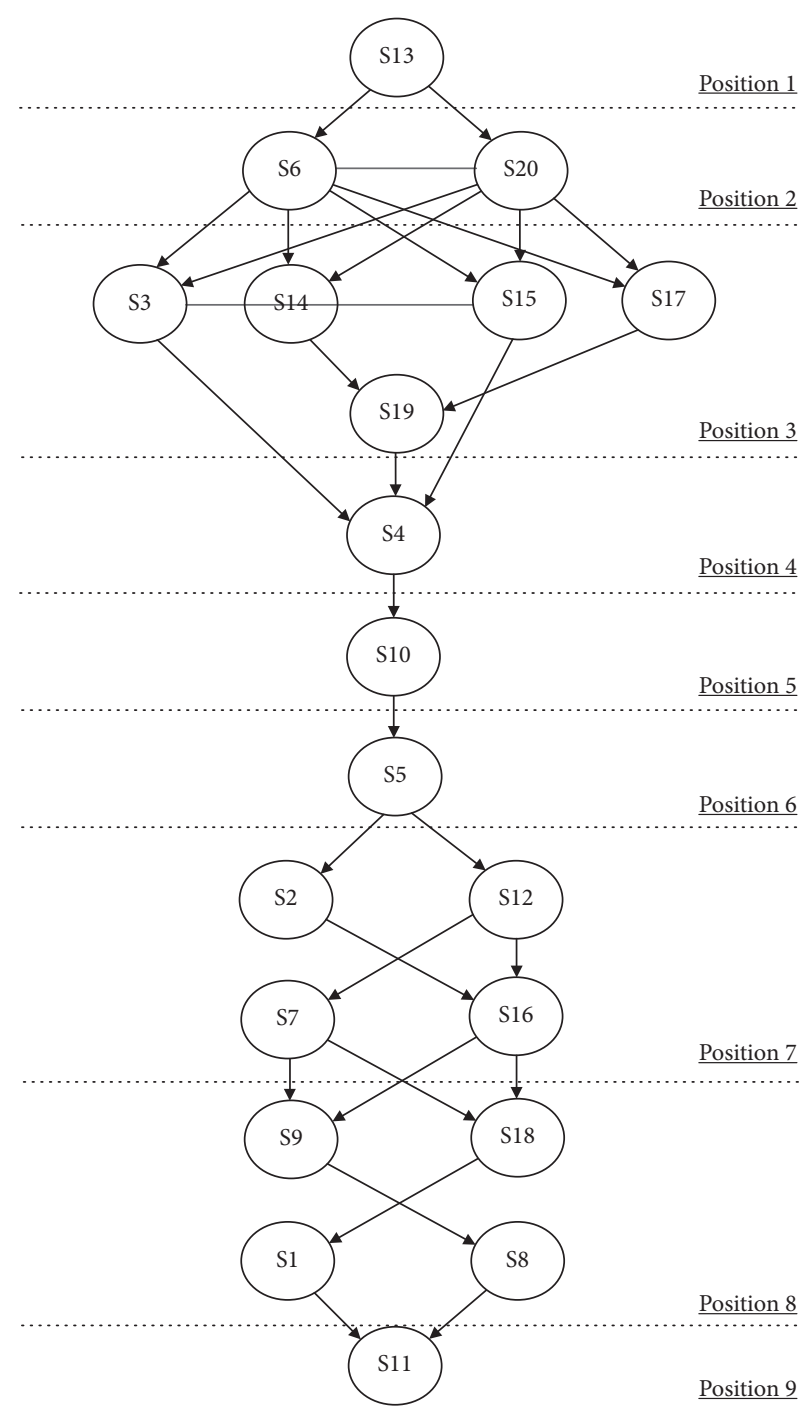

FIGURE 5: Hasse diagram after the fourth elicitation question.

[20, 21]. In bar graphics, the height of the columns represents the performance of alternatives in each criterion and in radar graphics the criteria are presented at the 
vertices and the best performance is reached at these extremities.

Thus, the first pair of graphics (see Figure 6) was constructed to evaluate the alternatives in the third position, S3, S14, S15, and S17. As alternatives S3 and S15 presented the same performance, S15 was excluded to simplify the representation. It is worth mentioning that these graphics represent the evaluation of the suppliers (in Table 3), after applying the interval scale.

Based on Figure 6, it could be observed that all the alternatives presented the same performance in the last criterion (contribution margin-C5), which was therefore excluded in order to simplify the analysis. Based on the minimum level of confidence needed to select the best alternative in a bar graphic developed by [5], a bar graph with three alternatives and five criteria presented $22 \%$ of probability of success $[19,20]$. However, a bar graph with three alternatives and four criteria presented 57\% of probability of success $[19,20]$. Thus, based on these results, another bar graphic was constructed, as illustrated in Figure 7.

In criteria that had highest scaling constants, Product Quality (C1) and time (C4), alternative S14 presented the highest performance, followed by alternatives S17 and S3, respectively. In criterion flexibility (C2), alternatives S3 and S17 were tied, and, for C3 (relationship), alternative S3 presented highest performance. Given the MAVT context, in which trade-offs between the performance of the alternatives and scaling constants should be evaluated, the DM can observe that S14 presented a better performance in the criteria with highest scaling constants; however, it presented the lowest performance in criteria $\mathrm{C} 2$ and $\mathrm{C} 3$, raising doubts over its superiority in the supplier selection problem.

On the other hand, comparing S3 with S17, they were equivalent in C1 (Product Quality) and C4 (time). Thus, considering only C2 (flexibility) and C3 (relationship), it was possible to observe that S3 presented the highest performance, supposing to be better than $\mathrm{S} 17$ in the graphic. Now, from comparing S3 and S14, C4 can be excluded, and S14 wins in $\mathrm{C} 1$ but presents high disadvantage in $\mathrm{C} 2$ and $\mathrm{C} 3$, raising doubts in the supplier selection problem.

In order to reinforce the discussion, a radar graphic was constructed to represent individually the performance of each alternative in the problem, as illustrated in Figure 8. Based on the radar graphic, the highest area covered is S3 followed by S17 and S14. Thus, the DM can assume based on the graphical evaluation that alternative S3 dominates S17, and alternative S17 dominates S14.

A second pair of graphics (see Figure 9) was developed to evaluate the alternatives in position seven, S2 and S12. Based on these graphics, it was possible to identify S12 as the best alternative. In Criterion C1, S2 presented the highest performance, but S12 presented high performances in the other criteria, excluding $\mathrm{C} 5$ in which the performances of those were low. Given a situation in which the performances of alternative S12 in the criteria C4 and C5 can be aggregated, they become approximately equivalent to the performance of S2 in Criterion C1. Thus, it can be suggested that S12 is the best alternative following the MAVT. Moreover, based on the radar graphic, the area covered by S12 is higher than that covered by S2.

The last evaluation was developed for alternatives $S 9$ and S18 presented in position eight. Based on Figure 10 and using compensatory rationality, alternative S18 presented better performance than S9 only in criterion C1, and it is equivalent to the performance of $\mathrm{S} 9$ in criterion $\mathrm{C} 4$. Therefore, it was possible to suggest that alternative S9 is better than S18 in the problem.

Therefore, based on the graphical visualization (see Figures $6-10$ ), the ranking can be updated by the holistic evaluation process. Also, as highlighted in the FITradeoff section, if the DM desires, he/she can stop the process at any point and obtain the final partial or complete ranking.

For this study, we identify that the order of the alternatives placed in the first 10 positions of the ranking is considered sufficient for the DM. Therefore, at this point of the decision process, the DM decided to stop the process and considered the partial ranking obtained using the elicitation process and the holistic evaluation, namely, S13, S6 = S20; S3 $=$ S15, S17, S14, S19, S4, S10, S5, and S12. Also, the scaling constant space obtained from the LPP model (in the system of equations (4)-(8)), following the preferences expressed by the DM during the FITradeoff process, presented the highest value of scaling constant for criteria $\mathrm{C} 1, \mathrm{C} 4$, and $\mathrm{C} 5$, with a value between 0.2 and 0.24 ; Criterion $\mathrm{C} 2$ presented scaling constant value between 0.13 and 0.2 ; and the criterion $\mathrm{C} 3$ presented scaling constant value between 0 and 0.09 , as shown in Figure 11. Unlike the Tradeoff method, the FITradeoff method generates a scaling constant space instead of the exact value of the scaling constants. Also, if the $\mathrm{DM}$ has provided different preferences for the pairwise comparisons, the scaling constant space would be different, since the LPP model would present different inequalities to accommodate these preferences expressed.

Unlike the Tradeoff method, the FITradeoff method generates a scaling constant space instead of the exact value of the scaling constants. Thus, for the problem under study, based on the preferences expressed by the DM, the first three criteria present the highest values of scaling constant, varying between approximately 0.24 and 0.29 . If the DM expresses different preferences in the process, the space would be different to accommodate the preferences expressed.

4.1.6. Establish Supply Contract. After applying the selection model and obtaining a ranking of the suppliers, the DM should analyze whether or not to approve the supplier. Thus, if the supplier is approved, it is recommended that a supply contract be drawn up.

4.2. Discussion. On applying the proposed supplier selection model, the importance of the supplier selection tool became evident. The FITradeoff method assists the DM in solving the problem based on a structured Linear Programming Program (LPP) model instead of following the DM's empirical 


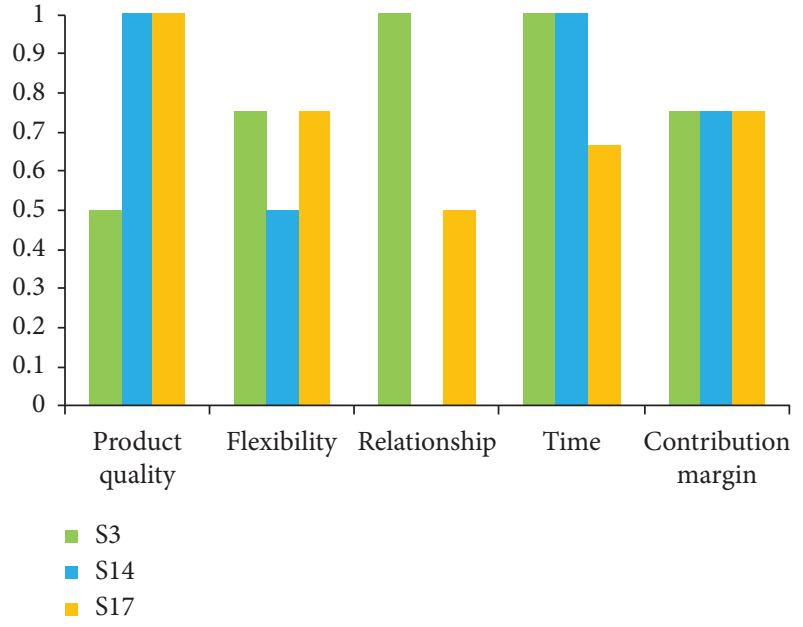

(a)

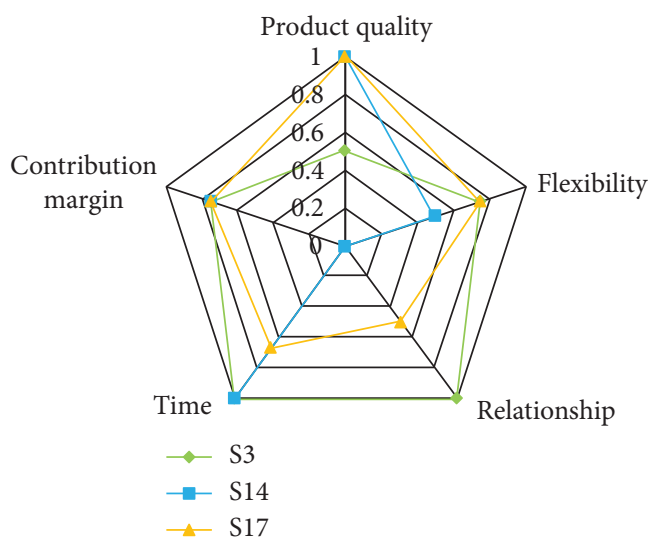

(b)

Figure 6: Graphics to evaluate alternatives in position three.

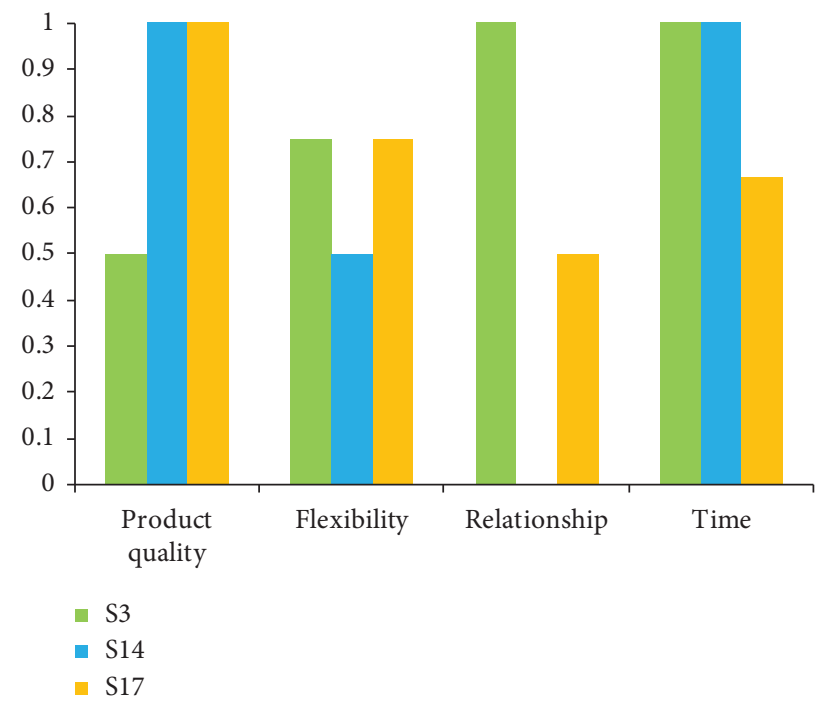

Figure 7: Bar graphic without criterion C5.

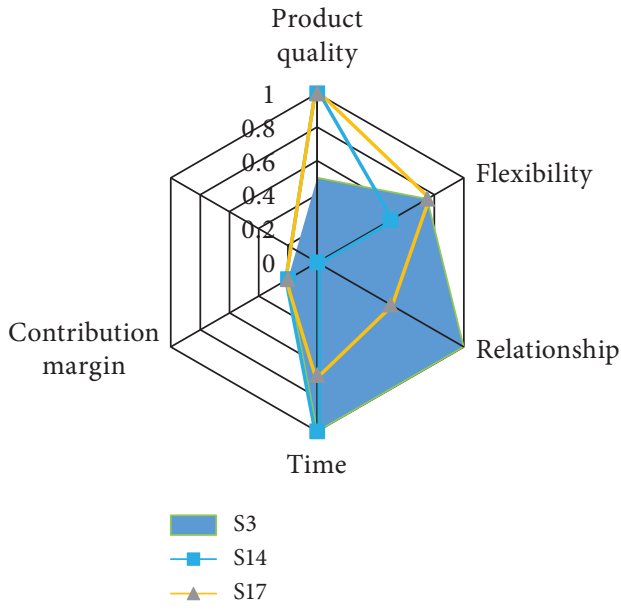

(a)

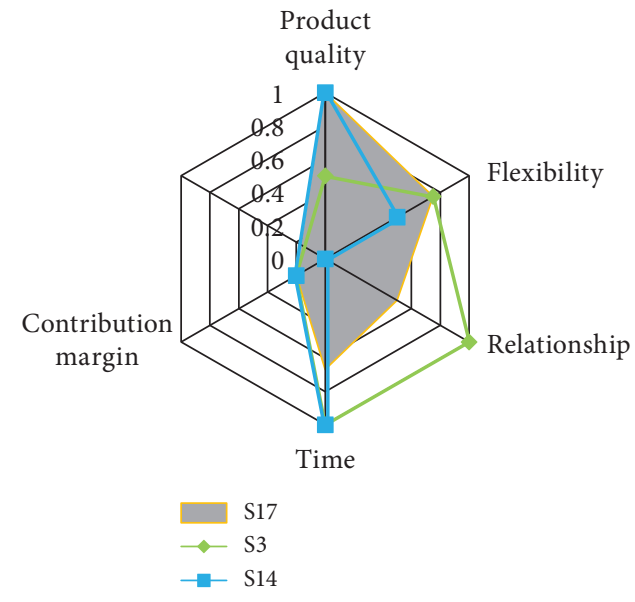

(b)

FIgUre 8: Continued. 


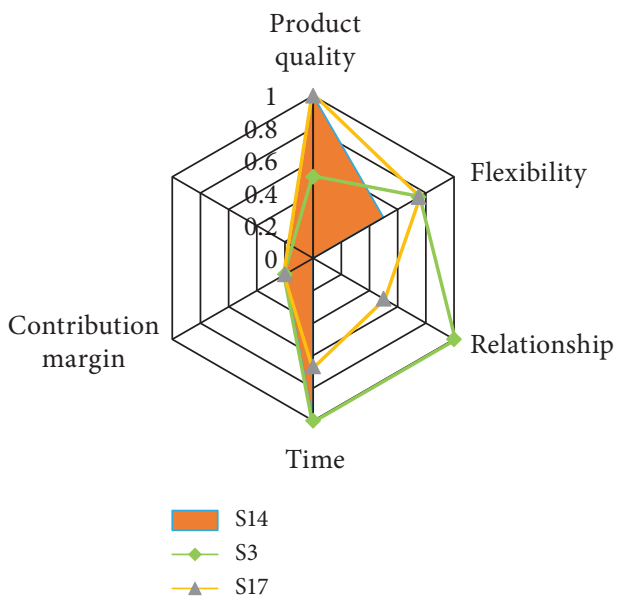

(c)

FIGURE 8: Radar graphic to compare alternatives S3, S14, and S17.

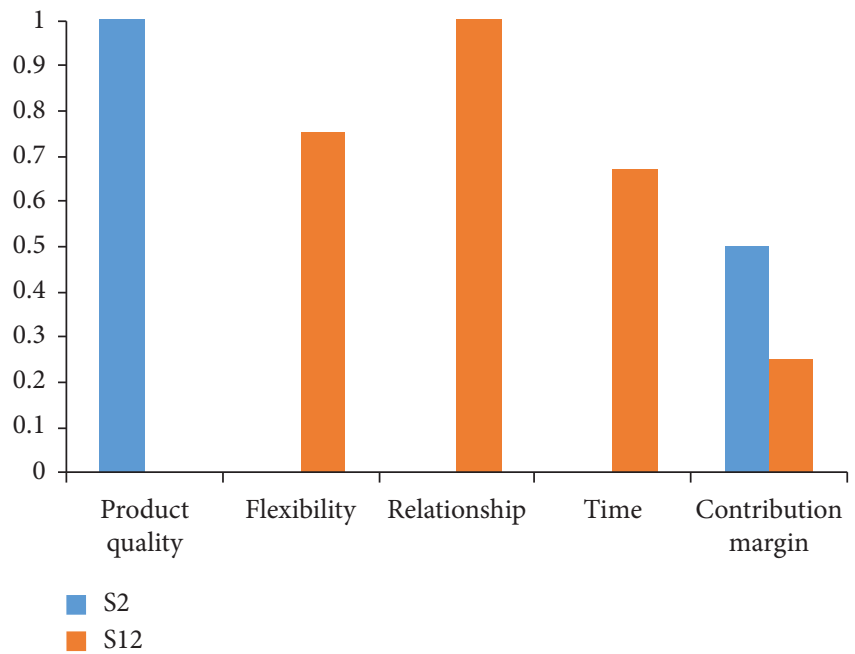

(a)

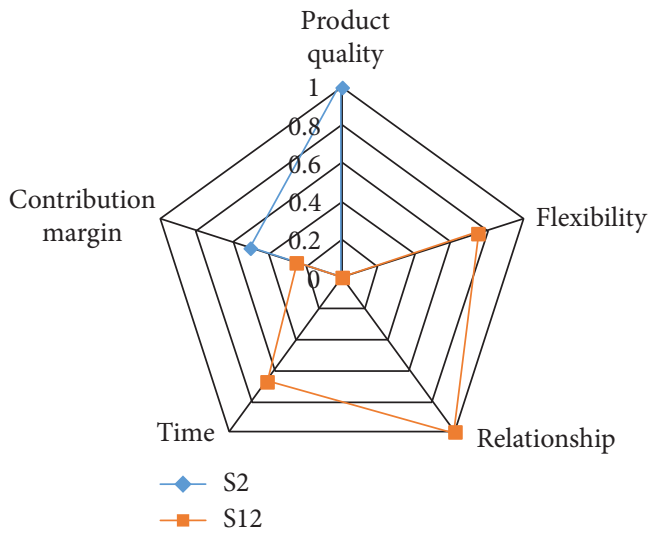

(b)

Figure 9: Graphics to evaluate alternatives in position seven.

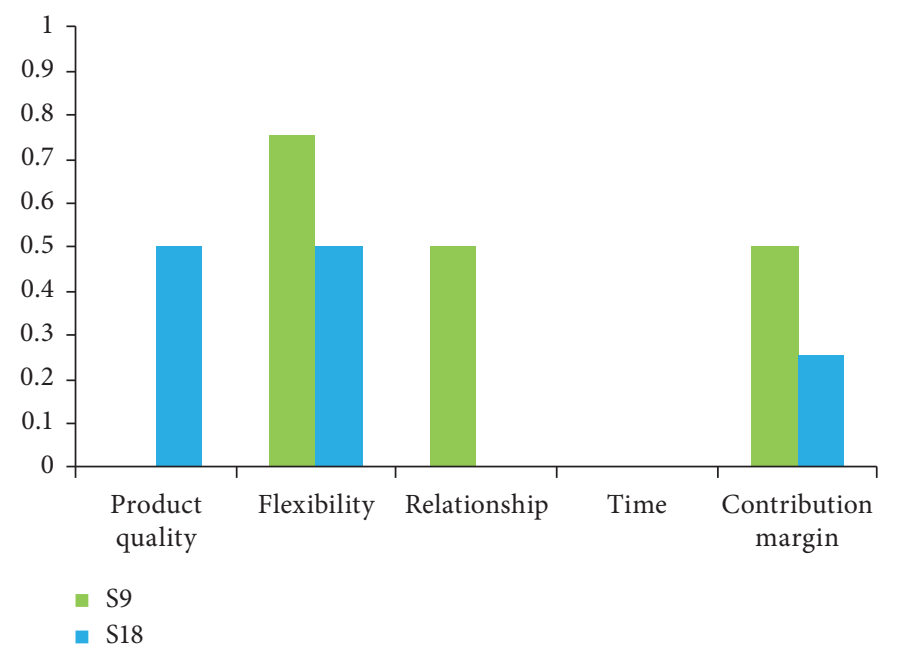

(a)

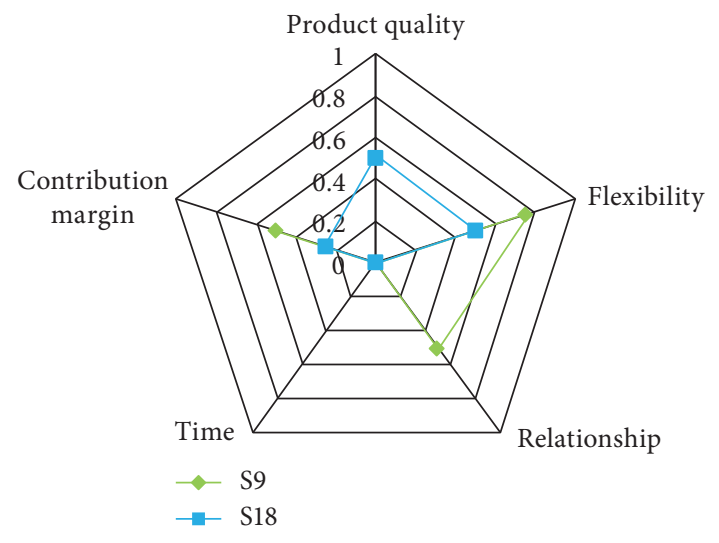

(b)

FIgUre 10: Graphics to evaluate alternatives in position eight. 


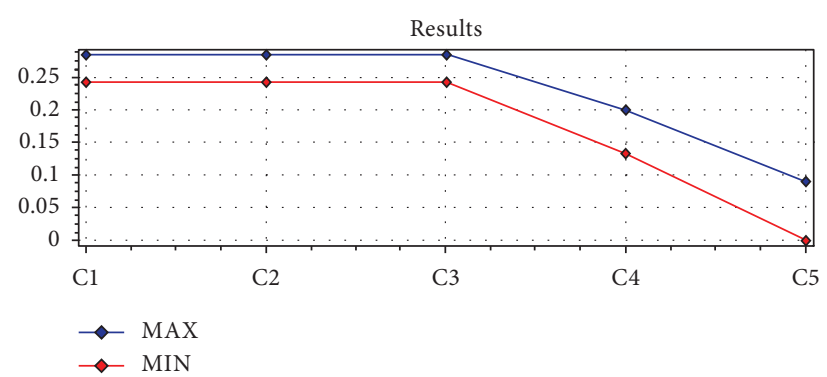

FIgURE 11: Scaling constant space.

knowledge about the situation faced. Therefore, the selection and approval of suppliers will be more judicious, which will generate greater confidence in the selection.

Some studies were developed regarding the theme supplier selection, as presented before. The study of Palha et al. [14] also presented a holistic model; nevertheless, the focus of their study was not a selection model but a categorization of services to be supplied in the civil construction. Araújo et al. [13] proposed a MCDM/A model for ranking suppliers in the food industry. Nevertheless, in their problem they had a group of decisionmakers involved in the selection process, being necessary to use a multicriteria method for group decision. A study using the FITradeoff method for a choice problem for supplier selection in a food manufacturer has already been developed [18]. Nevertheless, it had only five alternatives, presenting a typical case of a choice problematic.

In our study, although we use the same method, it is applied to a ranking problem which is a more robust problematic since this leads the DM to have more information than the choice problematic provides. The actual problem involved 20 alternatives, which shows that this is a complex MCDM/A problem with a large number of consequences for the DM evaluate. The problem is in the context of a waterproofing company, and the ranking was obtained enabling the DM to assess the alternatives placed in the first position of the ranking in order to assist the decision about which one was to be selected. Our study presented graphical visualization analysis, which contributes to supporting the DM during an MCDM/A problem. Also, these visualizations are a flexible tool which can improve the FITradeoff DSS.

Thus, the proposed model is an important managerial tool because it reveals what suppliers are the most suitable due to the fact that they meet the company's selection criteria. Therefore, FITradeoff proved to be a flexible and efficient method for the supplier selection problem, in which companies must define the direction and frequency of this process, depending on the type of alliance to be formed with their suppliers.

\section{Conclusions}

This study sought to propose a supplier selection model for a wholesaler and retailer of the construction sector, in order to assist the DM in the process of selecting new suppliers, with the objective of keeping the products and suppliers in line with the company's strategic plans and objectives. This process is crucial to the competitiveness and sustainability of the company's business and its supply chain as a whole.

This paper has demonstrated that, in a supplier selection process, several important criteria that are aligned with the strategic interests of the company must be included in the problem of deciding on the best supplier(s). Thus, the supplier selection process is a multicriteria decision problem. Several multicriteria decision models have been proposed in the literature to elicit DMs' preferences in supplier selection problems. However, traditional compensatory methods have become tiring, tedious, and difficult for DMs and have led to many inconsistencies when evaluating alternatives as they consistently fail to meet DMs' preferences, leading to DMs abandoning the methodologies or to the results having no credibility [16-18].

In order to overcome these problems of inconsistencies in the evaluation of alternatives, interactive decision models can lead to less inconsistency in the results by working with partial information on DMs' preferences. Providing partial information requires less effort from the DM during the elicitation process. The FITradeoff method used in this study is for ranking problems and uses tradeoff judgments provided by DM for an easier decision-making process. Elicitation is conducted interactively with the DM using a DSS, which provides graphical visualization to assist the DM in the analysis of preliminary results. Some DMs would like to use the graphical visualization and others do not. However, in a general way, the graphics are presented in the DSS to assist the DMs.

This study contributes to the empirical research on the applicability of the FITradeoff method to solve a supplier selection problem in the retail and wholesale sector, considering the ranking problematic. Thus, this study can demonstrate that the FITradeoff method can be applied to aid the DM in solving a supplier ranking problem in a more flexible way. Using a questionnaire applied through FITradeoff DSS, fewer and easier questions could be answered by the DM, providing graphs that facilitated the process of analyzing the ranking position of suppliers. Data visualization also supported the DM to understand and make his decision process faster and more reliable, considering the aspects that the company judged important to be approached.

One limitation of this study may be the analyst's lack of skill and knowledge in the interpretation of the data to guide the DM, in which neuroscience studies can be used to 
support the advising process performed by the analyst [19-21].

As a suggestion for future studies, it could be to identify standard criteria for selecting suppliers in companies in the same segment as the company in this study and to analyze how the proposed model would behave for companies in the same segment where the decision is made by a group of DMs.

\section{Data Availability}

The data used to support the findings of this study are included within the article.

\section{Conflicts of Interest}

The authors declare that there are no conflicts of interest regarding the publication of this paper.

\section{Acknowledgments}

This paper is part of a research study funded by the Brazilian National Research Council (CNPq) and by Coordenação de Aperfeiçoamento de Pessoal de Nível Superior-Brasil (CAPES), Finance Code 001.

\section{References}

[1] W. Ho, X. Xu, and P. K. Dey, "Multi-criteria decision making approaches for supplier evaluation and selection: a literature review," European Journal of Operational Research, vol. 202, no. 1, pp. 16-24, 2010.

[2] C. Guo and X. Li, "A multi-echelon inventory system with supplier selection and order allocation under stochastic demand," International Journal of Production Economics, vol. 151, pp. 37-47, 2014.

[3] M. C. B. de Araújo, L. H. Alencar, and C. M. de Miranda Mota, "Project procurement management: a structured literature review," International Journal of Project Management, vol. 35, no. 3, pp. 353-377, 2017.

[4] W. Xia and Z. Wu, "Supplier selection with multiple criteria in volume discount environments," Omega, vol. 35, no. 5, pp. 494-504, 2007.

[5] R. L. Keeney and H. Raiffa, Decisions with Multiple Objectives: Preferences, and Value Tradeoffs, Wiley, New York, NY, USA, 1976.

[6] A. T. de Almeida, C. A. V. Cavalcante, M. H. Alencar, R. J. Ferreira, A. T. Almeida-Filho, and T. V. Garcez, "Multicriteria and multiobjective models for risk, reliability and maintenance decision analysis," International Series in Operations Research \& Management Science, vol. 231, 2015.

[7] V. Belton and T. Stewart, Multiple Criteria Decision Analysis: An Integrated Approach, Kluwer Academic Publishers, Dordrecht, USA, 2002.

[8] A. J. Brito and A. T. de Almeida, "Modeling a multi-attribute utility newsvendor with partial backlogging," European Journal of Operational Research, vol. 220, no. 3, p. 820, 2012.

[9] A. T. de Almeida and F. M. Campello de Souza, "Decision theory in maintenance strategy for a 2-unit redundant standby system," IEEE Transactions on Reliability, vol. 42, no. 3, p. 401, 1993.
[10] A. T. de Almeida and R. Vetschera, "A note on scale transformations in the PROMETHEE V method," European Journal of Operational Research, vol. 219, no. 1, p. 198, 2012.

[11] P. H. C. Lins and A. T. de Almeida, "Multidimensional risk analysis of hydrogen pipelines," International Journal of Hydrogen Energy, vol. 37, no. 18, p. 13545, 2012.

[12] Y.-H. Chen and R.-J. Chao, "Supplier selection using consistent fuzzy preference relations," Expert Systems with Applications, vol. 39, no. 3, pp. 3233-3240, 2012.

[13] M. C. B. de Araújo, L. H. Alencar, and J. C. Viana, "Structuring a model for supplier selection," Management Research Review, vol. 38, no. 11, pp. 1213-1232, 2015.

[14] R. P. Palha, A. T. de Almeida, and L. H. Alencar, "A model for sorting activities to be outsourced in civil construction based on ROR-UTADIS," Mathematical Problems in Engineering, vol. 2016, p. 15, Article ID 923641, 2016.

[15] A. A. Salo and R. P. Hämäläinen, "Preference assessment by imprecise ratio statements," Operations Research, vol. 40, no. 6, pp. 1053-1061, 1992.

[16] A. T. de Almeida, J. A. de Almeida, A. P. C. S. Costa, and A. T. de Almeida-Filho, "A new method for elicitation of criteria weights in additive models: flexible and interactive tradeoff," European Journal of Operational Research, vol. 250, no. 1, pp. 179-191, 2016.

[17] E. A. Frej, A. T. de Almeida, and A. P. Costa, "Using data visualization for ranking alternatives with partial information and interactive tradeoff elicitation," Operational Research, vol. 19, pp. 1-23, 2019.

[18] E. Frej, L. Roselli, J. Almeida, and A. T. de Almeida, "A multicriteria decision model for supplier selection in a food industry based on FITradeoff method," Mathematical Problems in Engineering, vol. 2017, p. 9, Article ID 4541914, 2017.

[19] L. R. P. Roselli and A. T. de Almeida, "Analysis of graphical visualizations for multi-criteria decision making in FITradeoff method using a decision neuroscience experiment," Lecture Notes in Business Information Processing, pp. 42-54, Springer International Publishing, Berlin, Germany, 2020.

[20] L. R. P. Roselli, A. T. de Almeida, and E. A. Frej, "Decision neuroscience for improving data visualization of decision support in the FITradeoff method," Operational Research, vol. 19, no. 1, pp. 1-21, 2019.

[21] L. R. P. Roselli, E. A. Frej, and A. T. de Almeida, "Neuroscience experiment for graphical visualization in the FITradeoff decision support system," in Group Decision and Negotiation in an Uncertain World. GDN 2018. Lecture Notes in Business Information Processing, Y. Chen, G. Kersten, R. Vetschera, and H. Xu, Eds., Vol. 315, Springer International Publishing, Berlin, Germany, 2018.

[22] A. Sanayei, S. Farid Mousavi, M. R. Abdi, and A. Mohaghar, "An integrated group decision-making process for supplier selection and order allocation using multi-attribute utility theory and linear programming," Journal of the Franklin Institute, vol. 345, no. 7, pp. 731-747, 2008.

[23] S. Wibowo and H. Deng, "A fuzzy rule-based approach for screening international distribution centres," Computers \& Mathematics with Applications, vol. 64, no. 5, pp. 1084-1092, 2012.

[24] Z. Yang, Q. Xu, X. Qiu, and H. Wang, "An applied study on the method for supplier selection with PCA and ELECTRE," in Proceedings of the 2008 IEEE International Conference on Service Operations and Logistics, and Informatics, Beijing, China, 2008.

[25] H. K. Sarvestani, A. Zadeh, M. Seyfi, and M. Rasti-Barzoki, "Integrated order acceptance and supply chain scheduling 
problem with supplier selection and due date assignment," Applied Soft Computing, vol. 75, pp. 72-83, 2019.

[26] L. de Boer, E. Labro, and P. Morlacchi, "A review of methods supporting supplier selection," European Journal of Purchasing \& Supply Management, vol. 7, no. 2, pp. 75-89, 2001.

[27] Y.-J. Chen, "Structured methodology for supplier selection and evaluation in a supply chain," Information Sciences, vol. 181, no. 9, pp. 1651-1670, 2011.

[28] C. A. Weber, J. Current, and A. Desai, "An optimization approach to determining the number of vendors to employ," Supply Chain Management: An International Journal, vol. 5, no. 2, pp. 90-98, 2000.

[29] B. Karpak, E. Kumcu, and R. R. Kasuganti, "Purchasing materials in the supply chain: managing a multi-objective task," European Journal of Purchasing \& Supply Management, vol. 7, no. 3, pp. 209-216, 2001.

[30] S. Talluri and R. Narasimhan, "A methodology for strategic sourcing," European Journal of Operational Research, vol. 154, no. 1, pp. 236-250, 2004.

[31] S. B. Barla, "A case study of supplier selection for lean supply by using a mathematical model," Logistics Information Management, vol. 16, no. 6, pp. 451-459, 2003.

[32] S. H. Huang and H. Keskar, "Comprehensive and configurable metrics for supplier selection," International Journal of Production Economics, vol. 105, no. 2, pp. 510-523, 2007.

[33] C. Muralidharan, N. Anantharaman, and S. G. Deshmukh, "A multi-criteria group decisionmaking model for supplier rating," The Journal of Supply Chain Management, vol. 38, no. 4, pp. 22-33, 2002.

[34] F. T. S. Chan, "Interactive selection model for supplier selection process: an analytical hierarchy process approach," International Journal of Production Research, vol. 41, no. 15, pp. 3549-3579, 2003.

[35] J. Hou and D. Su, "EJB-MVC oriented supplier selection system for mass customization," Journal of Manufacturing Technology Management, vol. 18, no. 1, pp. 54-71, 2007.

[36] O. Bayazit, "Use of analytic network process in vendor selection decisions," Benchmarking: An International Journal, vol. 13 , no. 5 , pp. 566-579, 2006.

[37] C. Gencer and D. Gürpinar, "Analytic network process in supplier selection: a case study in an electronic firm," Applied Mathematical Modelling, vol. 31, no. 11, pp. 2475-2486, 2007.

[38] R. C. Baker and S. Talluri, "A closer look at the use of data envelopment analysis for technology selection," Computers \& Industrial Engineering, vol. 32, no. 1, pp. 101-108, 1997.

[39] J. Liu, F. Y. Ding, and V. Lall, "Using data envelopment analysis to compare suppliers for supplier selection and performance improvement," Supply Chain Management: An International Journal, vol. 5, no. 3, pp. 143-150, 2000.

[40] T. Wu, D. Shunk, J. Blackhurst, and R. Appalla, "AIDEA: a methodology for supplier evaluation and selection in a supplier-based manufacturing environment," International Journal of Manufacturing Technology and Management, vol. 11, no. 2, pp. 174-192, 2007.

[41] E. Timmerman, "An approach to vendor performance evaluation," Journal of Purchasing and Supply Management, vol. 1, pp. 27-32, 1986.

[42] D. L Smytka and M. W. Clemens, "Total cost supplier selection model: a case study," International Journal of Purchasing and Materials Management, vol. 29, no. 1, pp. 42-49, 1993.

[43] Z. Degraeve and F. Roodhooft, "Improving the efficiency of the purchasing process using total cost of ownership information: the case of heating electrodes at Cockerill Sambre
S.A.” European Journal of Operational Research, vol. 112, no. 1, pp. 42-53, 1999.

[44] C.-T. Chen, C.-T. Lin, and S.-F. Huang, "A fuzzy approach for supplier evaluation and selection in supply chain management," International Journal of Production Economics, vol. 102, no. 2, pp. 289-301, 2006.

[45] R. Florezlopez, "Strategic supplier selection in the added-value perspective: a CI approach," Information Sciences, vol. 177, no. 5, pp. 1169-1179, 2007.

[46] V. Albino and A. C. Garavelli, "A neural network application to subcontractor rating in construction firms," International Journal of Project Management, vol. 16, no. 1, pp. 9-14, 1998.

[47] L. P. Khoo, S. B. Tor, and S. S. G. Lee, "The potential of intelligent software agents in the World Wide Web in the automated part procurement," International Journal of Purchasing and Materials Management, vol. 34, no. 1, pp. 46-52, 1998.

[48] S. Ha and R. Krishnan, "A hybrid approach to supplier selection for the maintenance of a competitive supply chain," Expert Systems with Applications, vol. 34, no. 2, pp. 1303-1311, 2008.

[49] M. Weber and K. Borcherding, "Behavioral influences on weight judgments in multiattribute decision making," European Journal of Operational Research, vol. 67, no. 1, pp. 1-12, 1993.

[50] G. W. Dickson, “An analysis of vendor selection systems and decisions," Journal of Purchasing, vol. 2, no. 1, pp. 5-17, 1966.

[51] T. Choi and J. Hartley, "An exploration of supplier selection practices across the supply chain," Journal of Operations Management, vol. 14, no. 4, pp. 333-343, 1966. 